tion of worker polymorphism and foraging strategies in leaf-cutting ants ${ }^{1,10}$, and may be significant in other ant genera.

\section{Flavio Roces}

Theodor-Boveri Institut,

Lehrstuhl für Verhaltensphysiologie

und Soziobiologie der Universität,

97074 Würzburg, Germany

John R. B. Lighton

Department of Biology,

University of Utah, Salt Lake City,

Utah 84112, USA

\section{Nuclear DNA from primate dung}

SIR - Although hypervariable DNA markers have revolutionized the study of kinship patterns and mating systems in the wild $^{1,2}$, these techniques have largely been restricted to species that can be easily captured and handled. Where handling is either unsafe or impracticable, DNA must be obtained non-invasively ${ }^{3}$. Collecting hair or buccal cells can be difficult or impossible in many species, so the ideal system should be based on material that is both plentiful and can be attributed unambiguously to a specific individual. Following the extraction of mitochondrial and chloroplast DNA from bear dung, by Höss et al. ${ }^{4}$, we investigated whether useful samples of nuclear DNA could be obtained from the faeces of wild primates.

We collected dung from individually recognized olive baboons in the Gombe
Stream National Park, Tanzania ${ }^{5,6}$, and stored it first in liquid nitrogen, then in a $-20{ }^{\circ} \mathrm{C}$ freezer. We modified a protocol for extracting mitochondrial DNA from chimpanzee dung ${ }^{7}$, combining the techniques of $\mathrm{Pääbo}^{8}$ and $\mathrm{Boom}^{9}$ with a phenol/chloroform extraction with hexadecyltrimethylammonium bromide (CTAB) and collagenase. CTAB was added to the overnight incubation in order to break down ingested plant compounds that would inhibit subsequent PCR reactions. Extracted DNA was amplified using human nuclear microsatellite primer D4S243 (ref. 10) and PCR. As a control, we used chelex ${ }^{3}$ to extract DNA from hair of several of the same individuals. PCR products were inserted into TA cloning vector (Invitrogen) and transformed into Escherichia coli. Colonies were grown overnight, plasmids were isolated and sequenced with the M13 forward primer.

Nuclear DNA extracted from dung and hair reveals that the baboon sequence at the D4S243 locus aligns with the human sequence, exhibiting three base substitutions, four ambiguous codes, and deletions of 28 and 63 base pairs (see figure). Human microsatellite primers successfully amplify baboon DNA in a significant number of cases (J. Rogers, personal communication), and paternity exclusions can usually be achieved by amplifying six polymorphic loci. PCR amplification has been successful in 39 out of 40 faecal samples tested so far. The ability to amplify microsatellite regions from faecally extracted nuclear DNA

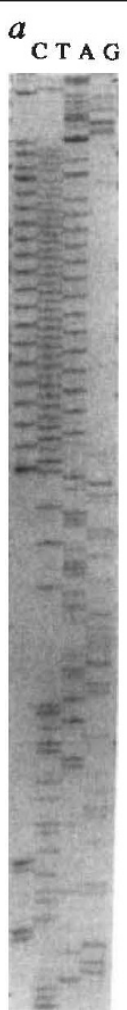

$b$

Human: TAGGAGCCTG TGGTCCTGTT GGTGTGAATT GTATTAGGAA GAGAGGAGAG

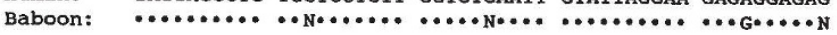

ATAAAAGATG TAAATGGAGA TCTGTCTGTC TACCTATCTA TCTATCCGTT

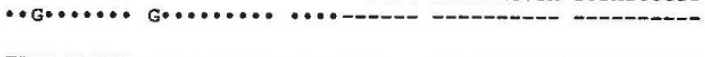

TATCTATCTA -

TCTATCTATC tatcatctat ctgcaaggag aAagagagac tgaAgagaAt

-...... • \%

GCAGGGTGAT AGAAAGGTAG AAAAGGGATT GAAATCATTG TTAAAAGGAA

TGAGAA

TGAGA

a, The D4S243 locus of a baboon, sequenced from the PCR amplification of faecal DNA. The fragment length is 169 base pairs, with a prominent tetra-repeat of 16 times. PCR amplification utilized a 40cycle "touch-down" program, terminating at $50^{\circ} \mathrm{C}$. Sequencing was achieved by inserting the PCR product into Invitrogen's TA cloning vector, and reactions were performed using Promega's cycle sequencing kit and a $6 \%$ denaturing acrylamide gel for $3 \mathrm{~h}$ at $55 \mathrm{~W}$. Visualization was accomplished with Promega's silver stain kit. $b$, The human D4S243 locus aligned with the extracted baboon sequence. Note the 28-base-pair deletion in the baboon sequence before the repeat region and the 63-base-pair deletion at the end of the fragment. The length of the repeat region may vary between individuals, thus allowing paternity and population-genetic studies. opens a new realm of possibilities for studying organisms that are difficult to catch or handle ${ }^{11}$. Dung should be considered essential material for paternity and population genetic studies of arboreal or endangered mammals.

\section{J. J. Constable*, C. Packer,}

\section{A. Collins, A. E. Pusey}

Department of Ecology,

Evolution and Behavior,

University of Minnesota,

St Paul, Minnesota 55108, USA

*Present address: Department of Biology, University of Nevada, Mailstop 314, Reno, NV 89557, USA.

1. Burke, T. Trends ecol. Evol. 4, 139 (1989).

2. Queller, D.C., Strasssman, J.E. \& Hughes, C. R. Trends ecol. Evol. 8, 285 (1993).

3. Morin, P.A. et al. Science 265, 1193 (1994).

4. Höss, M. et al. Nature 359, 199 (1992).

5. Goodall, J. The Chimpanzees of Gombe (Harvard Univ. Press, Cambridge, 1986).

6. Packer, C. et al. Nature 373, 60-63 (1995).

7. Goldberg, T. Biotechniques (in the press).

8. Pääbo, S., Gifford, J.A. \& Wilson, A.C. Nucleic Acids Res. 16, $9775-9787$ (1988).

9. Boom, R. et al. J. clin. Microbiol. 28, 495-503 (1990). 10. Hudsen et al. Genomics 13, 622 (1992).

11. Kohn, M. et al. Molec. Ecol. (in the press).

\section{Comparison of deep ice cores}

SIR - Comparison of the GRIP and GISP2 deep ice cores from central Greenland $^{1,2}$ has confirmed the occurrence of exceptionally large, rapid changes in many climatic indicators over approximately the past 100,000 years ${ }^{3,4}$. Similar rapid changes occur within deeper ice with a warm isotope signature (identified as the Eemian, Sangamonian, or stage $5 \mathrm{e}^{3,4}$ ), but differences in their patterns between the two cores raise the possibility that at least one record was disturbed by ice-flow processes $^{1,2}$. Disturbances might include boudinage, open folding or similar processes that would distort the timedepth relation but leave layers in stratigraphic order, or overturned folding that would disturb stratigraphic order. The GRIP and GISP2 steering bodies have initiated comparative studies of the two cores, including visible stratigraphy and crystal fabrics in selected sections of both cores, which are reported here. The most important results of these studies include the following.

(1) The small diameters of the cores and the lack of any highly reliable stratigraphic 'up' indicators prevent us from distinguishing overturned from right-side-up layers in structures much larger than the core diameter (13 $\mathrm{cm}$ for GISP2 and 10 $\mathrm{cm}$ for GRIP before sampling). We thus cannot invalidate or confirm the instability of the Eemian record.

(2) Both cores contain structures above the Eemian (which was identified as $2,790-2,865 \mathrm{~m}$ at $\mathrm{GRIP}^{3,4}$ ) that are larger than the core diameter and that could represent inverted strata. A $10-20-\mathrm{cm}$ long region of layers dipping $20^{\circ}$ relative 


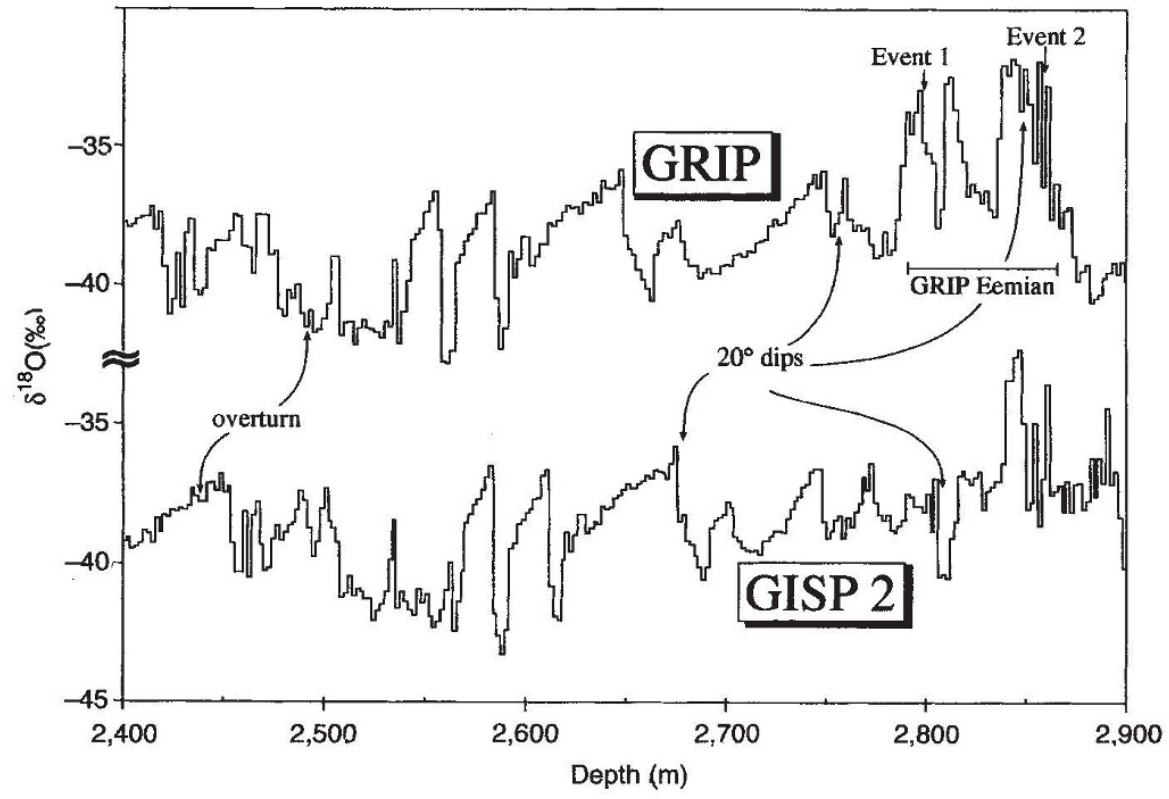

Oxygen-isotope compositions of the GRIP ${ }^{4}$ and GISP2 (ref. 2) deep ice cores. The shallowest overturned folds, and the shallowest two regions of steep dips, are indicated for each core. The depths of major features in the cores differ slightly owing to well-understood differences in snow accumulation and layer thinning; significant mismatch not explainable in this way occurs deeper than about $2,700-2,750 \mathrm{~m}$.

to the normal to the core axis, within a zone more than $1 \mathrm{~m}$ long of dips of $10^{\circ}$ or more (compared with a borehole inclination of about $2^{\circ}$ ), occurs at about $2,757 \mathrm{~m}$ in the GRIP core, and steep dips also are observed near $2,847 \mathrm{~m}$. In the GISP2 core, a $50-\mathrm{cm}$-long region with dips as steep as $20^{\circ}$ was observed at $2,679 \mathrm{~m}$, and a region several metres long with dips to more than $20^{\circ}$ occurs around $2,809 \mathrm{~m}$, with other regions of steep dips deeper (compared with a borehole inclination of about $5^{\circ}$ ). We cannot yet guarantee that these are the shallowest occurrences of disturbed features too large to be observed completely within a single core. Most of the ice around these features in both cores is less disturbed, although much disturbance is evident below the GRIP Eemian and below a similar level at GISP2. Significant mismatch between the palaeoclimatic records begins at about the same depth as the large deformational structures, but this correspondence is not exact and some deformation occurs without large mismatch.

(3) Both cores contain evidence of at least moderate simple-shear deformation (strains of the order of 10 or more), including $z$-shaped folds with overturned limbs smaller than the core diameter. Such $z$-shaped folds, millimetres high, appear as shallowly as 2,437 $\mathrm{m}$ at GISP2 and $2,483 \mathrm{~m}$ at GRIP with larger folds deeper, but those at GRIP do not appear as well-developed as those at GISP2 until the lower quarter of the Eemian $(2,847 \mathrm{~m}$ and below, including the margins of event 2 ; refs 2,3). The shear sense is consistent within each core. In both cores, the $c$-axis fabrics are affected by folding and regions of dips, indicating that deformation is ongoing or sufficiently recent (within about 3,000 years) that the fabric has not been reset by further deformation. GRIP today is near the ice divide, where flow patterns are not expected to produce stratigraphic discontinuities, whereas GISP2 is in a simple-shear, flank-flow regime where stratigraphic discontinuities are more likely. The simple-shear features observed at GRIP suggest recent or ongoing ice-divide migration ${ }^{5,6}$.

R. B. Alley*

A. J. Gow

S. J. Johnsen ${ }^{\ddagger}$

J. Kipfstuh! ${ }^{\S}$

D. A. Meese ${ }^{\dagger}$

Th. Thorsteinsson ${ }^{\S \uparrow}$

* Earth System Science Center and Department of Geosciences, The Pennsylvania State University, University Park, Pennsylvania 16802, USA

${ }^{\dagger}$ US Army Cold Regions,

Research and Engineering Laboratory, Hanover, New Hampshire 03755, USA

${ }^{*}$ The Niels Bohr Institute,

University of Copenhagen,

DK-2200 Copenhagen N, Denmark

$\S_{\text {Alfred-Wegener Institut für }}$

Polar und Meeresforschung,

Columbusstrasse,

27568 Bremerhaven, Germany

"To whom correspondence should be addressed.

1. Taylor, K. et al. Nature 366, 549-552 (1993).

2. Grootes, P. et al. Nature 366, 552-553 (1993)

3. GRIP Project Members. Nature 364, 203-207 (1993).

4. Dansgaard, W. et al. Nature 364, 218-220 (1993).

5. Hempel, L. \& Thyssen, F. Polarforschung 62, 6-11 (1992).

6. Anandakrishnan, S., Alley, R.B. \& Waddington, E.D. Geophys. Res. Lett. 21, 441-444 (1993).

\section{Back to front}

SIR - Lim et al. ${ }^{1}$ and Feng et al. ${ }^{2}$ showed that Src-homology-3 (SH3) domains can bind two classes of ligand that exist in opposite orientations on the proteincarbon backbone. These elegant studies represent an example of a protein-protein interaction in which the ligand sequence can exist in either $\mathrm{N} \rightarrow \mathrm{C}$ or $\mathrm{C} \rightarrow \mathrm{N}$ orientation. We have also demonstrated that antibody molecules can similarly recognize protein sequences presented in either orientation $^{3}$.

These various findings should sound a general warning to the scientific community regarding the use of protein databases for similarity searches to detect related binding motifs. Clearly, such searches should be performed in both forward and reverse carbon-backbone orientations; otherwise, up to half of the functional homology regions could be overlooked.

\section{Dennis W. Metzger}

Department of Microbiology,

Medical College of Ohio,

Toledo, Ohio 43699-0008, USA

Victor H. Van Cleave

Genetics Institute, Cambridge,

Massachusetts 02140, USA

1. Lim, W. A., Richards, F. M. \& Fox, R. O. Nature $\mathbf{3 7 2}$, 375-379 (1994)

2. Feng, S., Chen, J. K., Yu, H., Simon, J. A. \& Schreiber, S. L. Science 266, 1241-1247 (1994).

3. Van Cleave, V. H., Naeve, C. W. \& Metzger, D. W. J. exp. Med. 167, 1841-1848 (1988).

\section{Chromosome}

\section{correction}

SIR - Reese et al. (Nature 371, 523-527; 1994) published the isolation of two yeast TBP-associated proteins. One of them, named by the authors yTAFII90, corresponds to a gene that we have previously sequenced (L. M. et al. Yeast 10, $819-831$; 1994). In our paper, we mentioned the strong similarity of YBR1410 with the TAFII80 from Drosophila which was at that time the only known sequenced gene of this family. Reese $e t$ al. used our sequence present in the database, but they erroneously referred to chromosome III sequencing. Thus, we want to correct this point: YBR1410/yTAFII90 belongs to chromosome II (accession number S34023).

\section{Françoise Bussereau}

Nadine Démolis

Laurent Mallet

Michel Jacquet

Institut de Génétique et Microbiologie,

CNRS URA 1354,

Université de Paris-Sud,

Bâtiment 400,

91405 Orsay Cedex,

France 